Yasmín Martín Vodopivec

\title{
La práctica artística de Regina José Galindo: anatomía de una metáfora emancipatoria
}

Palabras clave: Regina José Galindo, lenguaje poético, performance en Guatemala, metáfora, emancipación

DOI: 10.4312/ars.11.2.365-382

\author{
Hay que decirlo \\ expresarlo \\ gritarlo \\ cantarlo \\ una y otra vez \\ como un mantra \\ un rosario \\ una letanía \\ hay que soltar la verdad \\ hay que soltar el grito. \\ Regina José Galindo
}

\section{Antecedentes del arte performance en Guatemala}

Las artes visuales en América Latina tuvieron en las décadas de los 80 y los 90, tal y como señala Iria Candela (2012), un auge similar al de la literatura en las dos décadas anteriores. Sobre las raíces del performance en este contexto "podría decirse que las intervenciones en vivo de artistas latinoamericanos- o de sus precursores no occidentaleshan tenido lugar desde la época precolombina incluyendo rituales y celebraciones culturales a la exhibición misma de sus cuerpos bajo condiciones coloniales» (Fusco, 1995, 37, en: Cullen, 2008, 229) y que empezó a desarrollarse como medio de expresión artística en un contexto político complejo en el que muchos países eran controlados por gobiernos militares o no democráticos. Teniendo en cuenta estas circunstancias, resulta más fácil comprender por qué es distintivo del arte de acción o performance en América Latina su carácter contestatario y su efectividad como herramienta de denuncia en las movilizaciones sociales relativas a la defensa de los derechos humanos.

En el caso de Guatemala, con una larga y turbulenta sucesión de dictaduras militares, marcada por una guerra civil que duró 36 años y que supuso no solo una 
estratificación social brutal basada en el racismo más absoluto hacia los indígenas sino que dio lugar a una represión continua perpetrada por el ejército y que provocó el genocidio maya (que dejó, según la ONU, alrededor de 200.000 víctimas, crímenes que hasta la fecha continúan prácticamente impunes), la trayectoria del arte performance es bastante diferente a la de otros países de América Latina.

El único antecedente registrado en el ámbito de la performance en Guatemala es el de Margarita Azurdia ${ }^{1}$, artista polifacética que realizó diversas acciones performativas durante la guerra civil guatemalteca y de las que casi no ha quedado documentación. Azurdia tuvo la oportunidad de formarse en el extranjero y destacó en un mundo dominado en aquel momento por hombres, siendo la primera artista centroamericana que participó en un evento internacional con un proyecto individual. Se trataba de la performance llamada Favor quitarse los zapatos (1970), que consistía en pedir al público que se quitara los zapatos antes de entrar a oscuras en una estructura de madera con el suelo cubierto de arena. Como otros artistas de esta época, Azurdia, «estaba interesada en integrar el cuerpo del público en la obra, explorando capacidades sensoriales distintas de la visión y ampliando la conciencia psicofísica.» (Cazali, 2011). Desde este experimento performativo, siguió explorando: organizó numerosos talleres para mujeres en torno a las danzas rituales, continuó escribiendo poesía y llevó sus acciones de la galería de arte al espacio público. En 1982, creó el llamado Laboratorio de Creatividad, a través del cual, en colaboración con otros artistas, presentó experiencias corporales atípicas en las que desarrollaba sus reflexiones sobre «el movimiento del cuerpo, su presentación y efecto en el espacio público y una conciencia sobre la importancia de insistir sobre su carácter disidente.» (Cazali, 2002).

Pero no fue hasta finales de los años noventa cuando la performance en Guatemala se convirtió en una importante herramienta de expresión, fomentada por un nuevo clima político de apertura, el restablecimiento de libertades y la recuperación del uso del espacio público.

\section{La práctica artística de Regina José Galindo}

Regina José Galindo, nacida en 1974, pertenece a la generación de artistas guatemaltecos que crecieron en los años de mayor violencia del país y que desarrollaron su carrera en los años de transición, de apertura política y de modernización que siguieron al final de la Guerra Civil en 1996. Es en ese mismo año cuando la Fundación

1 Artista guatemalteca (1931-1998) también conocida como Margot Fanjul, Margarita Rita Rica Dinamita, y Anastasia Margarita, fue una feminista, escultora, pintora, poeta y artista de performance interesada en la búsqueda de la representación del movimiento del cuerpo a partir de experiencias corporales llevadas a cabo tanto en galerías de arte como en espacios públicos que intentaba provocar la reacción del público. 
Coloquia publica el libro Personal e Intransmisible de la poeta Regina José Galindo. La artista, que dos años más tarde recibirá el Premio Único de Poesía de la Fundación Myrna Mack, es hoy la máxima representante del arte contemporáneo en Guatemala y una de las artistas de performance más influyentes, no solo en su país sino más allá del contexto latinoamericano.

Su incursión desde el ámbito de la poesía al de la performance surgió de manera natural, impulsada por la influencia de otros escritores y artistas (entre los que por su relación personal y dedicación a la performance destacan Jessica Lagunas y María Adela Díaz) con los que comienza a relacionarse en esos años y por la propia necesidad de Galindo de transmitir a través del cuerpo, que según sus palabras, siente que es el vehículo más directo que tiene para poder hablar (Galindo, 2012).

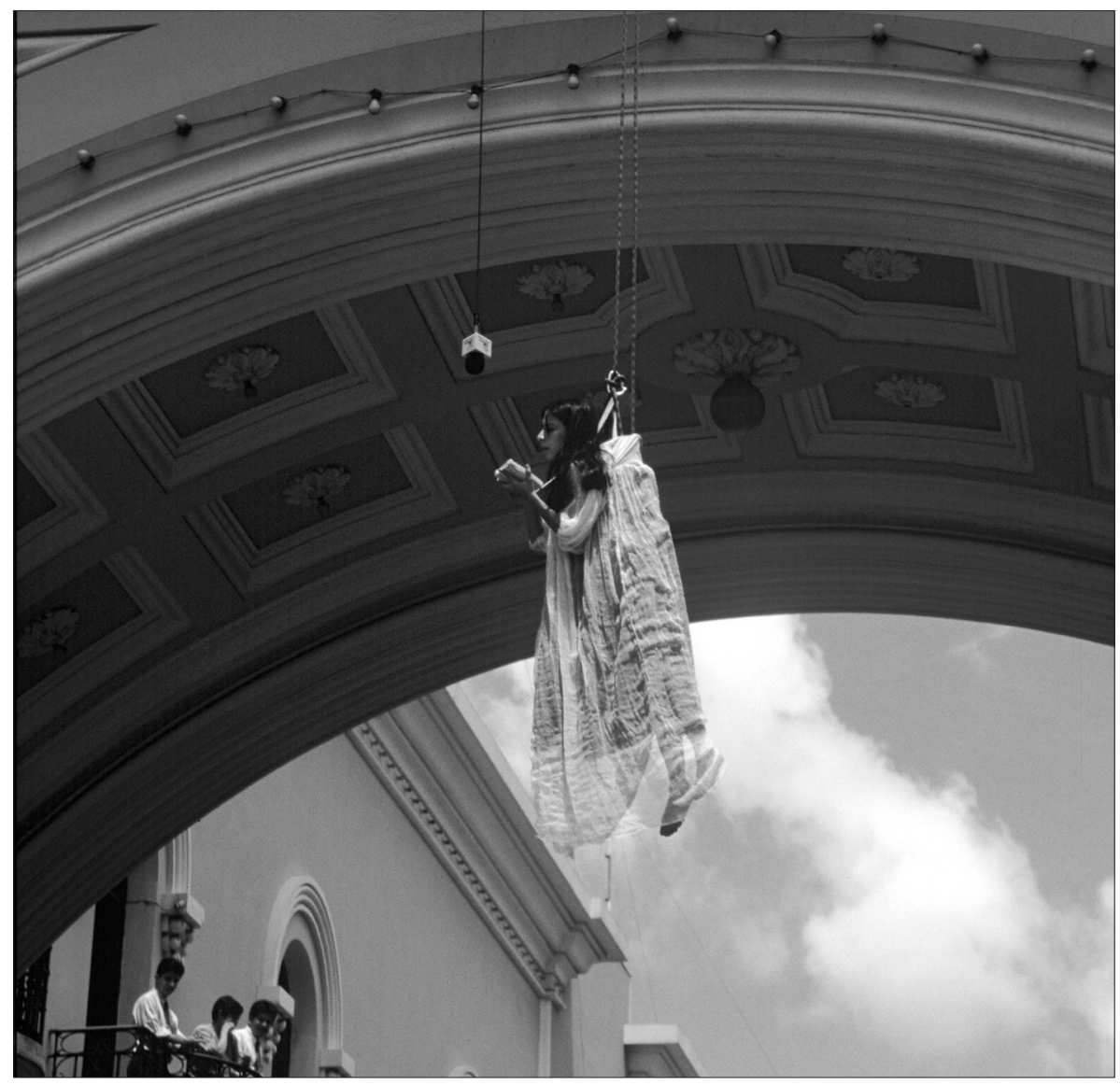

Figura 1: Lo voy a gritar al viento, 2011. Foto: Marvin Olivares y Ron Mocán. Cortesía de la artista. 
Es en febrero de 1999 cuando se presenta por primera vez como artista de performance en la exposición colectiva Sin pelos en la lengua, comisariada por el grupo PAI (Proyecto Arte Independiente) y considerada todavía en la actualidad como un evento clave al reunir entre sus participantes a los máximos exponentes del arte de acción de Guatemala (Pérez-Ratton, 2008, 210). Con su obra El dolor en un pañuelo, Galindo se muestra atada a una cama vertical mientras que sobre su cuerpo se proyectaban noticias de prensa para denunciar las violaciones y los abusos cometidos contra la mujer en Guatemala. A esta obra le siguió su primera performance presentada de manera individual y producida con el apoyo de la comisaria Belia de Vico, El cielo llora tanto que debería ser mujer, en la que al contener la respiración sumergida en una bañera, se despoja de la palabra y comienza a poner a prueba su cuerpo para transmitir la asfixia del silencio femenino. Es en ese mismo año, cuando se cuelga del Arco del Edificio de Correos de la ciudad de Guatemala, en la que es una de sus performances más emblemáticas, Lo voy a gritar al viento, para leer poemas y lanzarlos al aire de manera que los espectadores casuales pudieran recoger los textos inéditos con los que la artista denunciaba la represión de la sociedad tanto en el ámbito público como el privado.

Esta transición de la poesía a la performance no es un hecho aislado, pero en el caso de Regina José Galindo, será una constante en su carrera y definirá de manera precisa la obra de la artista. Desde el campo de la escritura, son muchos los que exploraron a través de las artes visuales, la música y la performance las posibilidades de la poesía más allá de la poesía. La performance como catalizador del mensaje a transmitir a través del sujeto, el objeto y la acción, establece conexiones formales y funcionales con el lenguaje poético, y con este gesto, la búsqueda de otro tipo de recepción que vaya más allá de lo establecido, de los límites habituales en los que se circunscriben a ambas disciplinas, resulta consustancial.

Las conexiones formales entre la poesía y la performance son abundantes, pero quizá una de las más destacables sea la cuestión del ritmo, y por ende, de la energía. El ritmo es considerado un elemento peculiar de la lengua poética, cuya función es distribuir coherentemente la energía. La poética formalista destacó la importancia del ritmo, incluso llegando a afirmar que cada poeta posee el suyo propio y peculiar. Como afirmaría Charles Olson en su manifiesto Verso proyectivo, en el que abogaba por una poética basada en el sonido y en la percepción más que en la sintaxis y en la lógica,

un poema es energía transferida desde donde la consiguió el poeta (él dispondrá de varias causas), pasando por el poema en sí mismo, y recorriendo todo el camino hacia el lector. Bien. Así, el poema debe ser, en todas partes, un constructo de alta concentración energética, y también, en todas partes, una descarga energética. (Olson, 2013, 370) 
Al igual que el sistema poético se consolida con la finalidad de llegar al público a base de procesos de creación y selección, en los esquemas sintácticos, las palabras y flexiones de las obras, los mecanismos en la performance funcionan de forma similar, ya que los mismos procesos influyen en la estructura y la función de los elementos de la obra performativa en los que también siempre hay un tercero que propicia que se abra un espacio en el que la acción se corporiza, ya sea a través del ritmo o la energía, con la suficiente intensidad como para crear un estadio de identificación en el que la posibilidad de interactuar a diferentes niveles se reafirma. Tal y como afirma la artista en una entrevista con motivo de la inauguración de la exposición Desierto en Chile:

[...] cuando un cuerpo se enfrenta a otro cuerpo hay esa transmisión de energía que es inevitable. Así, vas generando una experiencia en el público que es básicamente lo que a mí me interesa. El análisis va después de ver el performance. En el momento, lo que a mí me interesa es generar una experiencia personal que posteriormente no se va diluir, sino que se va a convertir en un debate. Eso es lo que pasa con el performance es energía pura. (Galindo, 2015)

En la segunda mitad del siglo XX, la poesía guatemalteca estuvo marcada por el compromiso político de los años cincuenta, y en décadas posteriores fue introduciendo nuevos temas como lo urbano, el feminismo, el cuerpo y la sexualidad; en concreto, la poesía de la posguerra guatemalteca está influenciada por el desarrollo de las nuevas tecnologías, el neoliberalismo y la globalización. Según Toledo y Acevedo (1999), son ellos los que introducen la imagen plástica y el ritmo visual, y revisan su historia colectiva desde la perspectiva de la cercanía del inicio de un nuevo siglo. La poesía de la generación nacida en los setenta, a pesar de estar marcada por la huella de la derrota, por los anhelos revolucionarios, la violencia extrema y la complejidad del proceso de transición, no suele reflejar estos aspectos de la historia directamente. Sus obras revelan desencanto, ironía, escepticismo, atrevimiento y provocación, sentimientos y actitudes que se desvelan en la obra tanto poética como performativa de Galindo.

Contreras Castro (2011) señala que en un momento en el que la ficción se plantea como una actitud apolítica, como una forma de escapar de la urgencia de trabajar a favor del cambio, en el que disociar el contexto político y social resulta imposible, en el que se produce un proceso de recuperación de las libertades y una vuelta al uso del espacio público, algunos escritores guatemaltecos deciden ampliar su experiencia poética, asumiéndola desde los distintos frentes que implican la visualidad de imágenes y su puesta en acción. Es de esa manera como se adentran en el ámbito del arte de acción, a través del cual exploran nuevos caminos por los que canalizar las perturbadoras consecuencias de más de treinta y seis años de guerra, genocidio y 
violación de derechos humanos. A ello también contribuye en gran medida un evento crucial e único en el ámbito de las artes visuales en Guatemala. En octubre del año 2000, a raíz de la iniciativa surgida de un colectivo de artistas, poetas y músicos que con anterioridad habían creado un laboratorio en el centro de Ciudad de Guatemala para la experimentación de híbridos disciplinarios y que se habían involucrado en diferentes festivales como el Primer Festival del Centro Histórico o el Festival de Arte Urbano, organizaron el Festival Octubre Azul para, de manera contestataria, dar respuesta a la institucionalidad y reabrir el espacio urbano, a través de la experimentación con diferentes lenguajes contemporáneos como la performance o la instalación, como plataforma para la legitimación y la expresión de la voz ciudadana. Concebido como una acción colectiva artística revolucionaria y amparándose en el derecho de manifestación de la Constitución Nacional, los resultados de este evento fueron un precedente indiscutible para las nuevas generaciones que comienzan a trabajar a partir de esta fecha. Considerada como la primera manifestación artística completamente contemporánea en la que «los contextos no relataban principalmente la guerra o la creación de una nueva nación, sino contextos de una nueva violencia y la necesidad de una sanación colectiva» (Pinto, 2015), este festival que no se volvió a repetir, creó una atmósfera de unión ciudadana y de intercambio de ideas sobre el papel del arte en el espacio público y el análisis de temáticas sociales de la violencia más allá del contexto de la guerra.

En el marco de este festival Regina José Galindo presentó su performance titulada No perdemos nada con nacer (2000), en la que se hizo arrojar metida en una bolsa de plástico transparente al vertedero municipal de Guatemala, el lugar donde de manera inadvertida acaban los despojos humanos cuyo destino es el de pasar a formar parte de una interminable lista de desaparecidos. Años más tarde, en 2017, llevó a cabo una performance similar, Desecho, en la que la artista documenta desde la oscuridad del interior de una bolsa plástico negra su recorrido incierto al ser ignorados sus sospechosos movimientos y ser recogida por un camión de basura del Estado Mexicano.

En las primeras acciones de Galindo, su relación con la poesía es más patente debido a la presencia de la palabra y la exploración de la carga poética del cuerpo desde una perspectiva primordialmente material, en la que el cuerpo inmovilizado se convierte al mismo tiempo en el sujeto y el objeto de la acción. En performances posteriores, desarrollará un proceso de prospección sobre la práctica artística de la performance para terminar planteando cuestiones colectivas incluso a través de la ausencia de la corporeidad. En la trayectoria performativa de la artista, la poética será una constante en su obra, independientemente de la ampliación de contenidos, la exploración de mecanismos diversos y el cambio de estrategias. 


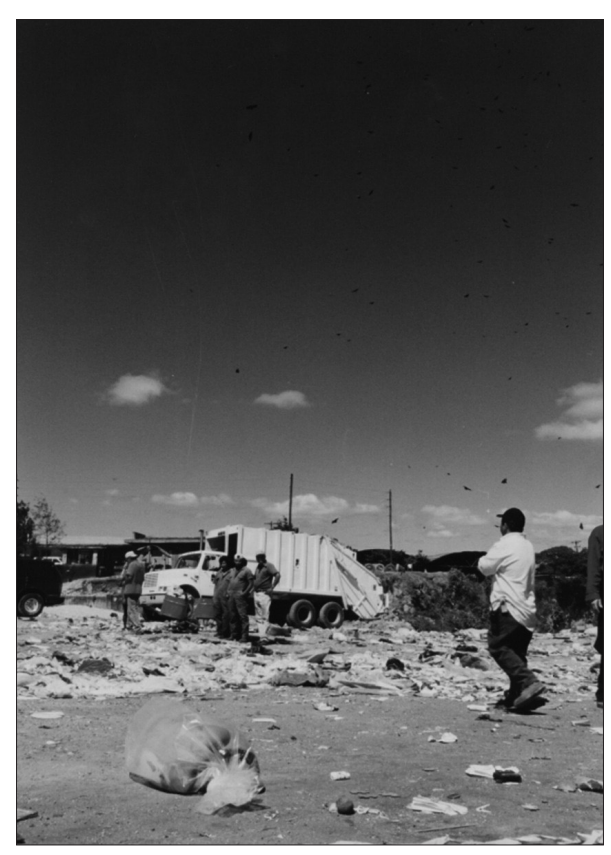

Figura 2: No perdemos nada con nacer, 2000. Foto: Belia de Vico.

Cortesía de Prometeo gallery di Ida Pisani.

Entre las acciones de la artista en las que la palabra está presente de manera visual, podríamos destacar la obra No violarás (2012) como texto impreso en una valla publicitaria a las afueras de Guatemala, y la obra de 2014, Genozide, en la que la artista durante su residencia en Berlín adaptó la célebre frase de Theodor Ludwig Wiesengrund Adorno a la propia realidad de Galindo, y desde su ventana colgó dos pancartas en las que se podía leer en alemán: «Escribir poesía después del genocidio es un acto de barbarie» - «En Guatemala también hubo genocidio»².

El texto inspirado por Adorno, que originariamente reflexionaba acerca de la posibilidad de hacer poesía tras los horrores de la guerra, sirve a la artista para cuestionar la producción artística y estética, las posibilidades y limitaciones del arte para narrar y explicar el pasado, así como para volver a repensar las cuestiones políticas y sociales más acuciantes en el contexto actual. Más allá de su función estética, el imaginario relativo a la poesía, contempla la responsabilidad del poeta como depositario del legado colectivo y responsable de materializar la intencionalidad de la poesía comprometida a través de la acción.

2 Tras la Segunda Guerra Mundial, el filósofo alemán de origen judío Theodor Ludwig Wiesengrund Adorno escribió en 1949 la controvertida frase: «Escribir poesía después de Auschwitz es un acto de barbarie», frase que el propio filósofo más tarde matizaría, pero que planteó la responsabilidad del artista respecto a un hecho traumático como el genocidio. 
La represión de los años anteriores a la paz había provocado una percepción social del cuerpo desnudo como un símbolo de castigo, relacionándolo con la tortura, la violación, el abuso. Regina José Galindo da un paso más allá e irrumpe en el mundo del arte empleando su cuerpo como herramienta para representar la marginalidad, aquí entendida incluso como individualidad frente a los otros en todas las posibles combinaciones de los marcos que nos han sido dados, desde la identidad a la colectividad, desgranados en todas sus aristas con una sutileza afilada en cada una de sus acciones. La ausencia se vuelve presencia, aunque solo sea dejándose presentir, y termina por ser reconocida y asumida como propia. La decepción es un sentimiento universal, porque

[...] sin duda el problema filosófico más infalible es el presente, de lo que somos en este preciso momento. Sin duda el objetivo principal en estos días no es descubrir lo que somos. Tenemos que imaginar y construir lo que podríamos ser para librarnos de este tipo de «doble atadura» política, que consiste en la simultánea individualización y totalización de las estructuras del poder moderno. (Foucault, 1988, 234)

Saber que no somos lo que podríamos ser, pero que podríamos ser lo que no somos; desvelar aquello que a pesar de existir no vemos, o aquello que existe tras lo que vemos, como Punto Ciego (2010), performance en la que expone su cuerpo desnudo en una sala expositiva a la que solo pueden acceder invidentes y en la que se desencadenan una serie de reacciones que cuestionan la naturaleza humana en contextos de impunidad social así como la poca consistencia de la percepción subjetiva respecto a los demás.

En sus acciones, cargadas de contenido simbólico, lo corpóreo representa la fragilidad del individuo, la dolorosa nimiedad de los otros y la sistemática vejación de los sistemas de poder. Y es esa otredad, diseccionada, la que hace que la obra de la artista dé lugar a todo excepto a la indiferencia. Los otros son siempre los otros, pero por alguna extraña razón terminamos siendo nosotros. Y es esa otredad, tan ajena y tan cercana, la que dispara el mecanismo por el que la «interpelación moral se produce.» (Butler, 2006, 164-165).

La función de sujeto social en la poesía guatemalteca, cuyo objeto era la realidad del contexto político y social del país, revierten en la práctica performativa de la artista, en un sujeto y un objeto que son el mismo y cuyas funciones van transmutando a lo largo de la trayectoria de la artista. Desde un sujeto y un objeto que coinciden, a un sujeto que se objetiva, o a otro que se objetiva para volverse a subjetivizar con la ayuda del que mira, hasta llegar a la objetivación de la propia práctica artística. Todo ello con el fin de construir metáforas relacionadas con la injusticia social, la fragmentación de la identidad, las discontinuidades de la memoria colectiva, las patologías sociales, 
las paradojas de los sistemas de poder y su silenciosa repercusión en los diferentes ámbitos de la vida cotidiana.

El problema de la función, la norma y el valor estéticos, las relaciones entre el arte y la sociedad, o la problemática del signo, no solo pertenecen a la literatura, sino que otros elementos que normalmente se circunscriben a este ámbito, como la imagen literaria tiene implicaciones importantes para la teoría de otras artes. La metáfora, considerada en el formalismo como parte del mundo de la poesía (en oposición a la metonimia, correspondiente al ámbito de la prosa), es un tipo de analogía o asociación entre elementos que comparten alguna similitud de significado para sustituir a uno por el otro en una misma estructura. En la práctica artística de Regina José Galindo, los elementos que conforman la constelación metafórica son: la artista, la acción y el observador. Este conjunto permite, al igual que en la metáfora en la poesía, ser interpretado como un solo concepto y funciona en las acciones de Galindo como un elemento de cohesión universal. La universalidad de la metáfora indica, tal y como sostenía Nietzsche, que el universo es concebido metafóricamente.

La función estética en la obra de la artista, refleja la relación dinámica que el arte mantiene con la sociedad a la que se dirige. Como señala el estructuralista Jan Mukařovský (2011), desde la perspectiva de la literatura, la función estética es una fuerza en constante movimiento que transforma los grados de percepción de una misma obra; no es una categoría estática que sirva para analizar el texto en sí mismo, por la valoración inherente con que haya podido ser creado. El potencial estético, en suma, se encuentra fuera del objeto artístico. Esta autonomía de la obra de arte, nos lleva a analizar el orden de la obra desde fuera, revelando lo que el filósofo alemán HansGeorg Gadamer consideró una autonomía basada en la soberanía del conocimiento y que le llevó a determinar que «El arte no es simplemente un instrumento de la voluntad socio-política: si es arte de verdad y no ha sido pensado como instrumento, documentará siempre una realidad social.» (Gadamer, 1993, 365). Esta autonomía, tanto externa como interna, es la que hace que la obra de Regina José Galindo plantee una experiencia emancipatoria.

\section{La metáfora performativa como experiencia empancipatoria}

La performance como acto de reafirmación de los cuerpos femeninos tradicionalmente ignorados o reprimidos por los hombres, en la que se expresa un rechazo explícito de las ideas tradicionales, que descartaban la sexualidad femenina, son el punto de partida de las acciones en las que la artista analiza la identidad desde diferentes perspectivas, abordando cuestiones de identidad de género, de 
identidad cultural o de identidad social. Cuestiona la posición social de la mujer a través de acciones como Esperando al príncipe azul (2001), en la que la artista yace bajo una sábana nupcial con una pequeña abertura a la altura de la vagina adornada por bordados, o Angelina (2001) en la que durante el mes que pasa como asistenta doméstica, ve cómo sus hábitos van cambiando hasta adaptarse a su nuevo estatus social, o cuando marca en su piel a cuchillo la palabra Perra (2005) evocando las inscripciones en los cuerpos de mujeres torturadas.

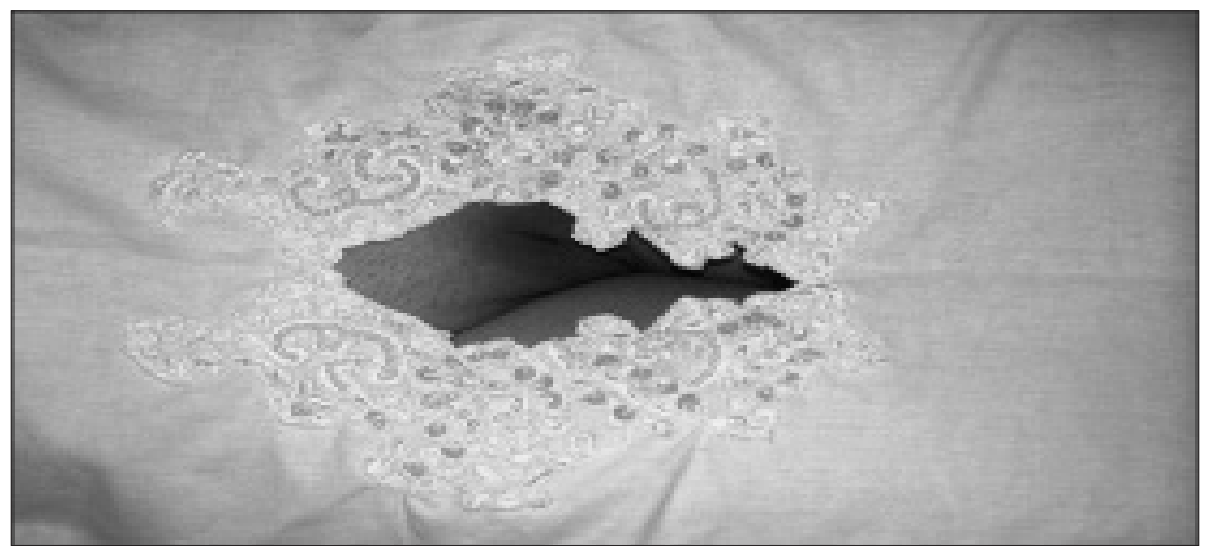

Figura 3: Secreto de estado, 2016. Foto: Neven Allgeier. Esperando al príncipe azul, 2001. Foto: Andrea Aragón. Cortesía de Prometeo gallery di Ida Pisani.

Denuncia los abusos cometidos a mujeres cuando en su performance Mientras ellos siguen libres (2007), con ocho meses de embarazo, la artista permanece atada con cordones umbilicales reales a una cama-catre, de la misma forma que las mujeres indígenas embarazadas eran amarradas para ser posteriormente violadas sistemáticamente durante el conflicto armado en Guatemala, o cuando ingiere un medicamento hipnótico utilizado comúnmente para realizar violaciones silenciosas y es despertada por dos hombres que le lanzan cubos de agua fría en su obra La Siesta (2016).

Cuestiona la discriminación, el terror y los abusos de poder, sin dar respuestas y provocando inquietud en el que observa. Obras como Hermana (2010) en la que el cuerpo ladino de la artista es abofeteado, escupido y castigado por una mujer indígena guatemalteca, La conquista (2009) en la que la exposición de los cabellos de mujeres indígenas y de la India, invoca a las mujeres víctimas del estraperlo que se ven forzadas a vender sus cabellos para subsistir, Limpieza social (2006) en la que es sometida a una ducha a presión con una manguera, tal y como se le realiza a los recién llegados a prisión o como método para aplacar manifestaciones, o cuando en su performance 
Secreto de estado (2016) los asistentes deben sostener una vieja y pesada camilla de guerra en la que la artista está acostada mientras su sangre gotea contra el suelo.

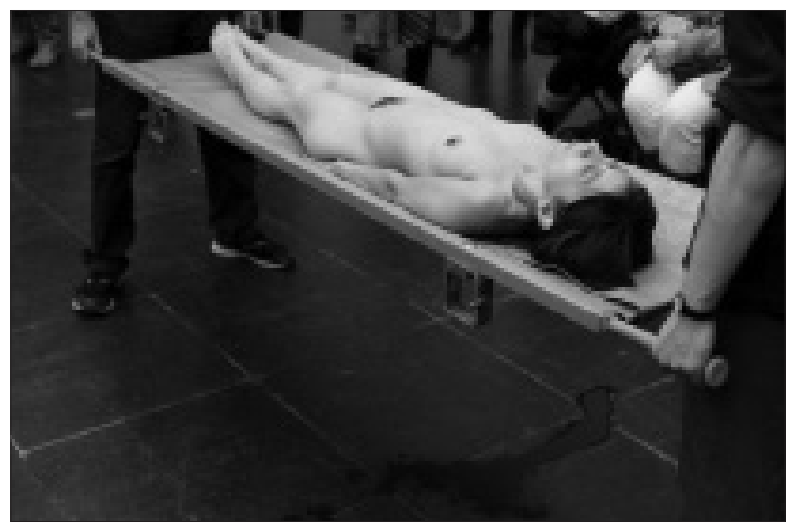

Figura 4: Secreto de estado, 2016. Foto: Neven Allgeier.

Mediante estrategias como el aislamiento, el encierro o la descalificación y a través de las cuales se produce la identificación, tal y como señaló Foucault $(1988,208)$ «el sujeto es objetivado, por un proceso de división, ya sea dentro de él mismo, o de los otros. En este proceso de objetivación, se le da una identidad social y personal a los seres humanos.» El sujeto objetivado en el cuerpo de la artista es un cuerpo colectivo, como cuerpo social se representa como objeto de «la materialidad del poder sobre los cuerpos mismos de los individuos.» (Rabinow, 1984, 10).

Además de las performances en las que la artista ejerce una acción sobre sí misma, están aquellas en las que cuenta con la participación de otros, ya sea como elementos integrados como parte de la performance o como espectadores activos que se involucran en la obra, viviéndola como una experiencia que puede llegar a desatar los mecanismos de cohesión social o llegar incluso a provocar una experiencia catártica.

Entre las obras en las que la artista involucra como parte de la performance a un colectivo para precisamente hablar de problemas sociales se encuentra Pelotón (2011), en la que contrata a cinco pelotones de policías de seguridad privada para formar filas frente a la Bandera Nacional en la Plaza de la Constitución, denunciando así que el número de guardias privados supera en Guatemala al de la Policía y el Ejército, a pesar de tratarse de un grupo sin instrucción que posee una baja escolaridad, está mal remunerado, y sin embargo fuertemente armado. Otro ejemplo ilustrativo sería la acción Quédate (2016) en la que un grupo de jóvenes alemanes sacuden y golpean el coche que conduce la artista guatemalteca hasta hacer saltar la alarma previamente manipulada para que suene como una alarma de guerra. 
Las desigualdades y las paradojas de la globalización llevan a la artista a crear performances en las que la ausencia de autonomía o incluso del cuerpo de la artista hacen que, al igual que en el contexto actual, la identificación y el reconocimiento se vuelvan herramientas imprescindibles para reconsiderar el papel de los cuerpos sociales. Esto lo podemos observar en obras como Looting (2010) en la que se hace incrustar por un dentista en Guatemala oro puro en los molares para ser extraídos más tarde en Alemania y ser expuestos como pequeñas esculturas en una galería, Juegos de Poder (2009) en la que cumple las órdenes de un hipnotizador, Un latino cerca de ti (2015) en la que inspirada por un proyecto del Departamento de Seguridad Nacional de Estados Unidos destinado a controlar a los individuos que cruzan ilegalmente las fronteras del país, registra sus pasos en dibujos hechos a partir de los movimientos de un GPS colocado su mi tobillo, o Escondite (2014) en la que tras un año para conseguir la visa alemana solo consiguió un permiso de 84 días para disfrutar de la residencia de artistas por lo que decide atarse a la parte inferior de su mesa de trabajo quedando de todos modos a la vista un cuerpo escondido, pero evidente.

En las performances en las que la artista aborda lo colectivo desde la perspectiva histórica, resulta especialmente llamativo su capacidad para reflejar el horror y la indignidad mediante el uso de «la estética de la violencia» ${ }^{3}$, para a través de signos, expresar la fragmentación de la identidad, el olvido y la desesperanza, no de una manera mimética, sino partiendo de una metaforización de la historicidad para hablar de conflictos de índole más existencial.

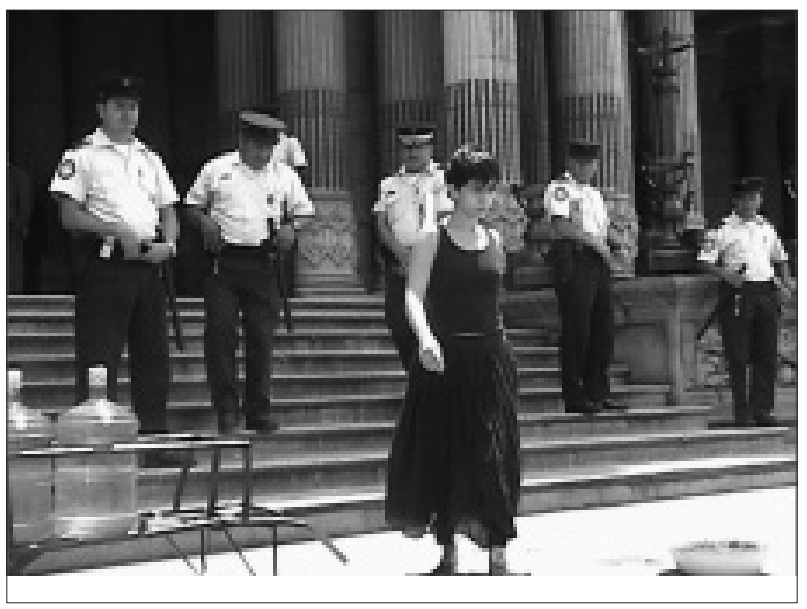

Figura 5: ¿Quién puede borrar las huellas?, 2003. Foto: Víctor Pérez. Cortesía de Prometeo gallery di Ida Pisani. 
En el año 2003, cuando la Corte constitucional guatemalteca aprobó la candidatura del ex-dictador Efraín Ríos Montt (que a pesar de haber sido condenado en 2013 a ochenta años de cárcel por genocidio y crímenes de lesa humanidad, sigue a día de hoy en libertad) a las elecciones presidenciales, la artista, con su performance titulada ¿Quién puede borrar las huellas? recorre las calles de la ciudad de Guatemala desde la Corte Constitucional al Palacio Presidencial, camino que Ríos Montt quería recorrer para volver a ser presidente, cargando una palangana llena de sangre humana. Cada pocos pasos se detenía, introducía sus pies en ella, para seguir luego caminando sobre el asfalto dejando un rastro de huellas de sangre. El sujeto como víctima y victimario. Las lagunas de la memoria, que resurgen para avisarnos que siguen ahí, que no se fueron tan lejos. El pasado colectivo es desvelado, extraído a la superficie por la artista, para volver a retomar su importancia en el contexto actual. Los cuerpos escondidos son descubiertos a la vista de los asistentes a la performance de manera inesperada. Como en Hilo del tiempo (2012), performance en la que su cuerpo oculto dentro de una bolsa tejida para cadáveres debía ser deshilachada o en Suelo común, acción concebida especialmente para ser ejecutada en el marco de la Bienal de Artes Gráficas de Liubliana (2013), en la que la artista permaneció enterrada durante dos horas en una zona boscosa del Parque Tivoli bajo un cristal blindado, esperando a ser caminada como esa superficie ordinaria que recorremos en nuestra vida diaria, ignorando quizás la existencia enterrada de un pasado incómodo.

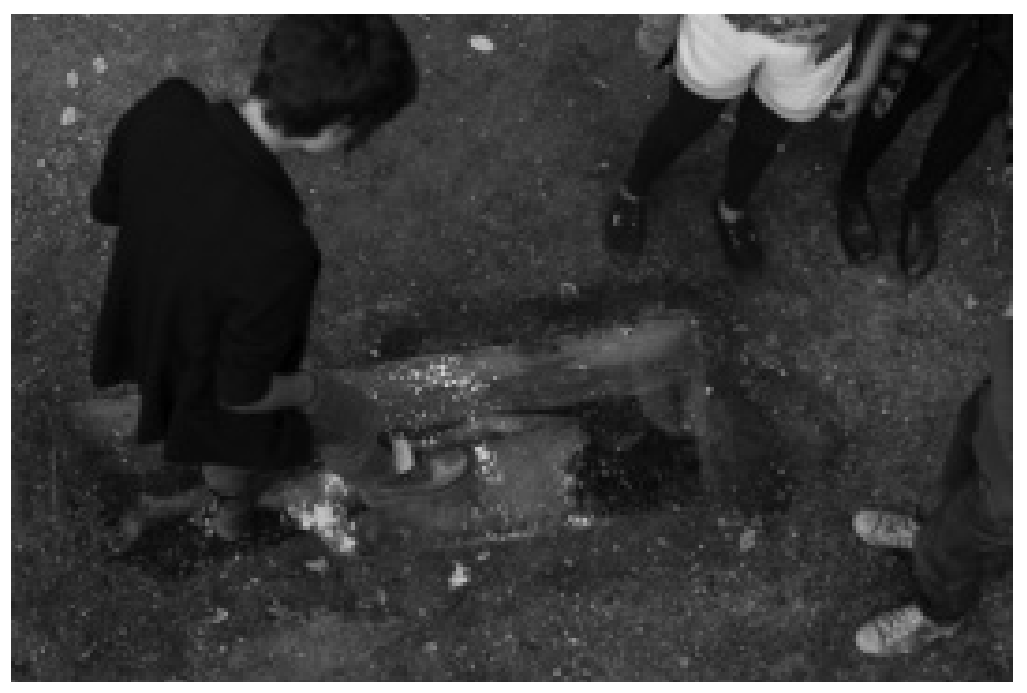

Figura 6: Suelo común, 2013. Foto: Jaka Babnik. Cortesía del Centro Internacional de Artes Gráficas (MGLC). 


\section{Conclusión}

Es en el reflejo de cada uno de nosotros en lo colectivo, en las metáforas performativas de Regina José Galindo en las que se produce una identificación universal abstracta, que hace que el que mira se identifique con el objeto, para luego disentir, y volverse a identificar, aunque sea a través de una percepción imprecisa, pero al final siempre reforzada por la mirada del otro. Un otro que es uno mismo cuando se ve reflejado en ese otro que ahora es el objeto. Una imagen, en la que nos vemos reflejados y que inmediatamente vuelve de regreso hacia nosotros como si rebotase, porque en cierto sentido, todas las acciones de Regina «funcionan como un espejo pero también tienen algo de disparo que da en el blanco.» (Castro Flórez, 2011, 25). Aquello que acierta en el blanco, es la representación real que es el arte, cuando el que observa enlaza lo que ve con lo que ya le es propio. Participa de la performance rehaciéndola a su manera, sustrayéndose a la energía vital que ésa debería transmitir, para hacer de ella una pura imagen y asociar esa pura imagen a una historia que ha leído o soñado, vivido o inventado (Rancière, 2010, 19) y compone su propia metáfora con los elementos que tiene delante y sus experiencias previas.

La efectividad del reflejo es inversamente proporcional a la distancia. Regina José Galindo desdeña la distancia entre su saber y nuestra ignorancia, asumiéndola como una condición implícita a toda contemplación artística. Como ella misma afirma «el arte del performance plantea interrogantes, no da respuestas» (Galindo, 2012) y es por este motivo por lo que le interesa crear experiencias «donde se modifiquen o desplacen las relaciones lineales entre el público y la obra de arte. Romper los esquemas es necesario en todo proceso de transmisión de información, para que el conocimiento no se estanque.» (Galindo, 2013).

En su trabajo no hay denuncia, solo la invitación a vivir una experiencia. La artista no nos muestra los caminos de su saber, pero está dispuesta a darnos las herramientas para emprender nuestro camino, al abandonar la aparente pasividad del que contempla y dejarnos llevar por la fuerza transgresora de la poética de sus acciones, para trascender nuestras capacidades sensibles y alcanzar la plenitud de la experiencia emancipatoria.

\section{Bibliografía}

Acevedo Leal, A., La estética de la violencia: Deconstrucciones de una identidad fragmentada, Temas Centrales. Primer simposio centroamericano de prácticas artísticas y posibilidades curatoriales contemporáneas, San José 2000, pp. 97-107. Butler, J., Vida precaria. El poder del duelo y la violencia, Buenos Aires 2006. 
Candela, I., Contraposiciones: Arte contemporáneo en Latinoamérica 1990-2010, Madrid 2012.

Castro Flórez, F., Las encarnaciones atroces de Regina José Galindo, Regina José Galindo, Milán 2011.

Cazali, R., Favor quitarse los zapatos. Re.Act. Feminism: A performing archive, 20112013, http://www.reactfeminism.org [29. 8. 2017]

Cazali, R., Últimas tardes con Margarita, El Periódico, 9 de marzo de 2002, http://www. elperiodico.com.gt/ [29. 8. 2017]

Contreras Castro, A., Despolitizar como acción política en la Centroamérica contemporánea, E-misférica 8/1, New York 2011, http://hemisphericinstitute.org/ hemi/es/e-misferica-81/contreras [29. 8. 2017].

Cullen, D. (ed.), Arte $\neq$ Vida. Actions by Artists of the Americas. 1960-2000, New York 2008.

Foucault, M., Por qué estudiar el poder: la cuestión del sujeto, en: Drezfus, H. L., Rabinow, P., Michel Foucault: más allá del estructuralismo y la hermeneútica, México, 1988, pp. 230-255.

Gadamer, H. G., Verdad y Método I y II, Salamanca 1993.

Grammatikopoulou, C., Ritual, realidad y representación: Desde el teatro antiguo hasta la performance postmoderna, Interartiv 48, 2013.

Jakobson, R., Lingüística y poética. Ensayos de lingüística general, Barcelona 1975.

José Galindo, R., Entrevista con Regina José Galindo en el programa Semáforo de Radio U. de Chile, 8 de julio de 2015, http://radio.uchile.cl/ [29. 8. 2017].

José Galindo, R., Entrevista con Regina José Galindo en el programa documental Metrópolis, dirigido por María Pallier, Radio televisión española, 16 de marzo de 2012, http://www.rtve.es/alacarta/videos/metropolis/metropolis-regina-josegalindo/1356005/ [29. 8. 2017]

José Galindo, R., Entrevista con Regina José Galindo: retrato hablado (Beatriz Colmenares), El Periódico de Guatemala, 25 de marzo de 2012, https://elperiodico. com.gt/es/20120325/pais/209978 [29. 8. 2017].

José Galindo, R. (s.f.), Biografía de Regina José Galindo en la página del Encuentro Internacional de Medellín, Colombia, http://mde.org.co/mde11/es/artistas/ regina-jose-galindo/ [29. 8. 2017].

Martín Vodopivec, Y., José Galindo, R., Lección de anatomía, Prekinitev. Katalog 30. grafični bienale Ljubljana, London, 2013, pp. 219-227.

Mukařovský, J., Función, norma y valor estético como hechos sociales, Madrid 2011.

Olson, Ch., Verso proyectivo, Buenos Aires, Bajo la luna, 2013. 
Pérez-Ratton, V., Performance and Action Work in Central America, 1960-2000: Apoliticaland Aesthetic Choice, en: Arte $\neq$ Vida. Actions by artists of the Americas 1960-2000 (ed. Cullen, D.), New York 2008, pp. 205-215.

Pinto, J., Sobre la importancia de la eternidad: Generación, Encuentro profesional/ diagnóstico, esQuisses 05, 2015, http://www.esquisses.net/2015/05/sobre-laimportancia-de-la-eternidad-generacion-encuentro-profesionaldiagnostico/ [29. 8. 2017].

Rabinow, P., The Foucault Reader, Nueva York 1984.

Rancière, J., El espectador emancipado, Castellón 2010.

Steiner, P., El formalismo ruso. Una metapoética, Madrid 2001.

Toledo, A., Acevedo, A., Cuando el poeta novísimo despertó la tradición todavía estaba allí, en: Tanta imagen tras la puerta. Poetas guatemaltecos del siglo XXI (eds. Acevedo, A., Toledo, A.), Ciudad de Guatemala 1999, pp. 11-17.

Valdés, S., Poéticas de la imagen digital, Cuadernos del Centro de Estudios en Diseño y Comunicación, 41, Buenos Aires 2012, pp. 203-215. 


\section{Yasmín Martín Vodopivec}

\section{Umetniška praksa Regine José Galindo: anatomija emancipacijske metafore}

Ključne besede: Regina José Galindo, pesniški jezik, performans v Gvatemali, metafora, emancipacija

V preteklosti so se številne študije odnosu poezije z drugimi umetnostmi posvečale predvsem s primerjalnega vidika. Pesniški jezik pa presega meje književnosti in postane ključni dejavnik pri opredeljevanju določenega dela kot umetnosti. Oblika, percepcija in izvedba performansa, ki je bil izvorno povezan $\mathrm{z}$ na besedilu osnovanim uprizoritvenim delom, kot umetniškega načina izražanja $\mathrm{v}$ latinskoameriškem kontekstu postane kritično sredstvo pri družbenih mobilizacijah, povezanih $\mathrm{z}$ varovanjem človekovih pravic. Glavna predstavnica performativne umetnosti v Gvatemali, Regina José Galindo (rojena leta 1974), je svojo pot začela na področju poezije. Njena performativna dejanja so formalno in funkcionalno povezana $s$ pesniškim jezikom, saj metafore ustvarja skozi subjekt, objekt in dejanje. Ti služijo kot katalizatorji sporočila, ki ga želi prenesti, in izzovejo druge vrste recepcijo, presegajočo običajne meje, ki zamejujejo obe disciplini. Umetničine performativne metafore se ukvarjajo z družbenim položajem ženske, hkrati pa dosežejo, da opazovalec skozi poistovetenje doživi polnost emancipacijske izkušnje. 


\section{Yasmín Martín Vodopivec}

\section{The artistic practice of Regina José Galindo: anatomy of an emancipatory metaphor}

Keywords: Regina José Galindo, poetic language, performance in Guatemala, metaphor, emancipation

Through history, the relationship between poetry and the other fine arts has been an object of numerous studies based mainly on comparative criteria. Poetic language transcends the boundaries of literature, and becomes a key element to determine if a work is indeed a work of art. The form, perception and execution of the performance, which in its origins was linked to the representative act based on the text as an artistic form of expression, is in the Latin-American context transformed into a protest element in the social mobilisations related to the defence of human rights. The main exponent of performance art in Guatemala, Regina José Galindo (born in 1974), started her career in the field of poetry. Her performances establish formal and functional connections with poetic language, creating metaphors through the subject, object and action, that are used as a catalyst of the message to be transmitted and thus create another type of reception, one that goes beyond the everyday limits that circumscribe both disciplines. The performance metaphors of the artist, besides questioning the social position of women, enable the observer to reach, through identification, the emancipatory experience in its entirety. 